\title{
Thrust Reduction of Magnetic Levitation Vehicle Driven by Long Stator Linear Synchronous Motor
}

\author{
Wan-Tsun Tseng \\ Department of Electrical Engineering, National Yunlin University of Science \& Technology, 123 University Road, Section 3, \\ Douliou, Yunlin 64002, Taiwan \\ Correspondence should be addressed to Wan-Tsun Tseng; tsengwt@yuntech.edu.tw
}

Received 10 September 2013; Accepted 20 October 2013

Academic Editor: Teen-Hang Meen

Copyright (C) 2013 Wan-Tsun Tseng. This is an open access article distributed under the Creative Commons Attribution License, which permits unrestricted use, distribution, and reproduction in any medium, provided the original work is properly cited.

\begin{abstract}
The propulsion technology of long stator linear synchronous motors is used to drive high-speed maglev trains. The linear synchronous motor stator is divided into sections placed on guideway. The electric power supplies to stator sections in which the train just passes in change-step mode for long-distance operation. However, a thrust drop will be caused by change-step machinery for driving magnetic vehicle. According to the train speed and vehicle data, the change-step mode has three types of operation, namely premature commutation, simultaneous commutation, and late commutation. Each type of operation has a different thrust drop which can be affected by several parameters such as jerk, running speed, motor section length, and vehicle data. This paper focuses on determining the thrust drop of the change-step mode. The study results of this paper can be used to improve the operation system of high-speed maglev trains.
\end{abstract}

\section{Introduction}

High-speed maglev systems for public transportation have been introduced for a long time. Typical examples are the Transrapid series in Germany [1-4] and the MLX series in Japan [5-7]. Both propulsion systems operate with long stator linear synchronous motors [8-11]. Although the maglev system in Germany can already go into commercial operation, the improvement of propulsion technology is still ongoing.

The propulsion system of the high-speed maglev train is devised to operate in different modes, depending on whether it is used in a short- or long-distance line. The propulsion system needs a high thrust to accelerate the train at startup so that the stator sections are connected using a three-step structure. This three-step structure consists of three sets of converter and power-cable systems $[10,12]$. In contrast to the three-step structure, however, a change-step structure requires only two. In order to reduce investment costs of substations, the propulsion system of the maglev train will be designed to use the change-step mode when the train travels at a constant speed $[13,14]$. In addition, stator winding loss can also be reduced significantly because power is only supplied to the segment over which the train just passes.
Therefore, when the train is about to leave the current stator section, the power supply should be switched off timely. And the power must be transferred to the next stator section. Such a process can result from turning off and on line switches (vacuum breakers) along the guideway.

Since the stator current should be adjusted up or down during stator section changing, the thrust will also be affected. Such thrust reduction can lead to a speed drop because the propulsion energy is reduced. Therefore, determining the thrust reduction has become an important issue for driving a maglev train using the change-step mode. Influential parameters on thrust are jerk, running speed, stator section length, and vehicle data. Among them, the jerk (in the unit of $\mathrm{m} / \mathrm{s}^{3}$ ) and running speed are most important. These influential parameters will be quantified in the following analysis.

\section{Description of Chagne-Step Mode}

The change-step mode is used to reduce line power losses, to improve the utilization of the installed power capacity of substations, and to increase the availability of the drive system 


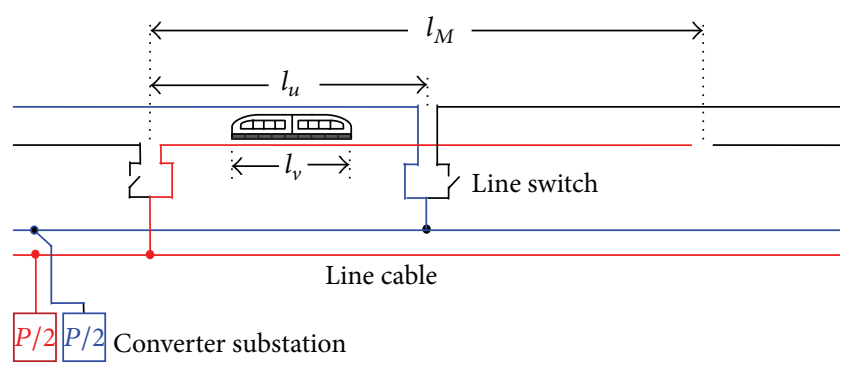

$l_{M}:$ Stator section length

$l_{u}$ : Overlap length

$l_{v}$ : Vehicle length

FIGURE 1: Propulsion system in change-step mode.

accordingly. The principal design of the change-step structure is depicted in Figure 1. The long stator motor sections at both sides of the guideway are installed in a staggered manner $[9,14]$. The overlap length $l_{u}$ must be longer than one train in length $l_{v}$ for minimizing the thrust losses due to a stator section change. The linear motor sections on the leftand right-side of the guideway are supplied by independent power sources. The electric power from the substation can be transferred through line switches to the corresponding stator motor sections where a train is located, as shown in Figure 1. If the train is leaving a section, the present stator current must be adjusted to zero and the line switch connected to that stator section will be opened subsequently. After the current stator section has been disconnected from the power source, the new stator section can receive the power by closing its associated line switch. And, then, the stator current of the newly connected stator section will be increased to a full load condition to drive the vehicle. This process repeats when the train travels for every change from a current stator section to the next.

\section{Three Operation Modes}

Based on various needs of commercial operations, the travel time between start point and destination is made flexible so that the maglev train Transrapid is not driven at the same speed for every trip constantly. According to the boundary condition of every trip, three different change-step modes can be classified by comparing the change time $t_{C}$ and commutation time $t_{K}$ as follows:

(i) premature commutation, $t_{C}<t_{K}$,

(ii) simultaneous commutation, $t_{C}=t_{K}$, or

(iii) late commutation, $t_{C}>t_{K}$.

The process of alternating the stator current between down and up is termed commutation and the corresponding time is referred to as commutation time $t_{K}$. And the elapsed time from the beginning to the end of a change is defined as the change time $t_{C}$.

Among the three modes, considering the reference speed $v_{S}$ under simultaneous commutation $\left(t_{C}=t_{K}\right)$ is quite reasonable, because we can determine the type of commutation in comparison with this speed. However, the case of the simultaneous commutation is relatively rare, because the operating speed usually deviates from the reference speed. If the train speed is greater than the reference speed of simultaneous commutation, premature commutation is used. On the contrary, when the train is moving slower than the reference speed of simultaneous commutation, late commutation should be taken. To obtain the reference speed of simultaneous commutation, the change time $t_{C}$ and commutation time $t_{K}$ must be calculated first. Letting $l_{v}$ be the vehicle length, the change time and commutation time can take from (1) and (2), respectively

$$
\begin{gathered}
t_{C}=\frac{l_{v}}{v} \\
t_{K}=\frac{F_{N}}{m r}+t_{S},
\end{gathered}
$$

where $m$ is the vehicle mass, the switch time $t_{S}$ remains constant for $500 \mathrm{~ms}, r$ is the limited jerk, and $F_{N}$ represents the rated thrust that is created by the corresponding running resistance. Given $t_{C}=t_{K}$, the reference speed $v_{S}$ of simultaneous commutation can be found from the following equation:

$$
\frac{l_{v}}{v_{s}}=\frac{F_{N}}{m \cdot r}+t_{s} .
$$

The running resistance of the maglev train Transrapid is composed of three parts, namely linear generator $F_{\mathrm{LG}}$ [15], eddy current from guidance $F_{E}$ [15], and aerodynamic resistance $F_{A}[16]$, as expressed in (4)-(7)

$$
\begin{gathered}
F_{\mathrm{LG}}=0[\mathrm{kN}], \quad v<100 \mathrm{~km} / \mathrm{h} \\
F_{\mathrm{LG}}=n_{c}\left(\frac{3.6 P_{\mathrm{LG}}}{v}-0.2\right)[\mathrm{kN}], \quad 100 \mathrm{~km} / \mathrm{h} \leqq v \leqq 500 \mathrm{~km} / \mathrm{h}
\end{gathered}
$$

$$
\begin{gathered}
F_{E}=n_{c}\left[0.1 \sqrt{\frac{v}{3.6}}+0.02\left(\frac{v}{3.6}\right)^{0.7}\right][\mathrm{kN}] . \\
F_{A}=0.216 \cdot 10^{-3}\left(\frac{0.53 n_{c}}{2}+0.3\right)(v+\Delta v)^{2}[\mathrm{kN}] .
\end{gathered}
$$

Parameters in (4)-(7) are defined as follows: $v$ : train speed in $\mathrm{km} / \mathrm{h}, \Delta v$ : side wind speed in $\mathrm{km} / \mathrm{h}, P_{\mathrm{LG}}$ : output power of linear generator in $\mathrm{kW}, n_{C}$ : the total number of cars. $F_{N}$ depends on $v^{-1}, v^{0.5}, v^{0.7}$ and $v^{2}$, so $v_{S}$ can be numerically solved from (3). Note that $v_{S}$ is not fixed but varies when different vehicle data are in use. With reference to the reported information of vehicle TR-09 [17], where a car is 50 tons and $25 \mathrm{~m}$ long on average, reference speeds for different vehicles are listed in Table 1.

\section{Calculation of Thrust Drop}

For a maglev train running at a constant speed, the change step mode operation provides a periodic thrust drop. The 


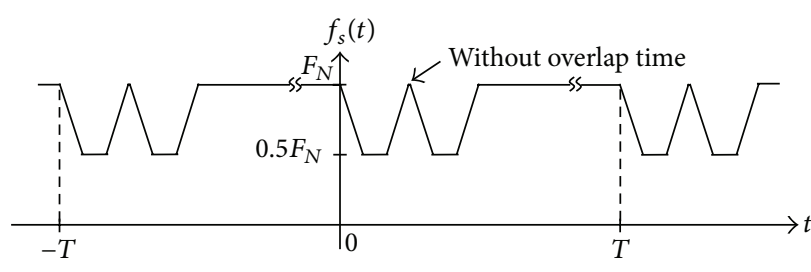

(a) Stator section changing without overlap time

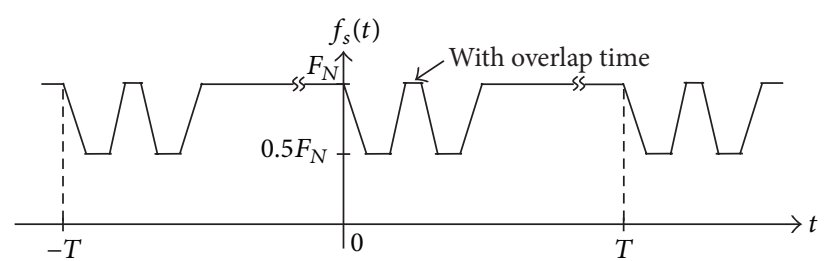

(b) Stator section changing with overlap time

FIGURE 2: Periodic thrust drop in change-step mode.

TABLE 1: Reference speed $v_{S}$

\begin{tabular}{lcccc}
\hline \multirow{2}{*}{ Jerk $\left(\mathrm{m} / \mathrm{s}^{3}\right)$} & \multicolumn{4}{c}{$v_{\mathrm{S}}(\mathrm{km} / \mathrm{h})$} \\
\hline 0.1 & 4 -car & 5 -car & 6 -car & 8 -car \\
0.2 & 200 & 233 & 261 & 306 \\
0.3 & 267 & 333 & 339 & 394 \\
0.4 & 307 & 351 & 388 & 451 \\
0.5 & 336 & 384 & 425 & 494 \\
\hline
\end{tabular}

overlap time $t_{u}$ can be obtained by overlap length $l_{u}$ shown in Figure 1. As mentioned in Section 2, the overlap length is set between vehicle length $l_{v}$ and half of the stator section length $l_{M}$. If $l_{u}=l_{v}$, the overlap time is defined as zero $\left(t_{u}=0\right.$, as shown in Figure 2(a)). Figure 2(b) indicates that the overlap time is greater than zero. The period $T$ of thrust time curve depends on travel speed and stator section length and can be determined by $(8)$

$$
T=\frac{l_{M}}{v} .
$$

The thrust drop is a negative effect of the maglev train operating in change-step mode. It should be as small as possible. In order to know the influence on the thrust drop, the arithmetic value of the thrust can be calculated according to (9)

$$
F_{\mathrm{av}}=\frac{1}{T} \int_{-T / 2}^{T / 2} f_{s}(t) d t
$$

From Section 3, the calculation of the average thrust can be divided into three parts, namely premature commutation $\left(t_{C}<t_{K}\right)$, simultaneous commutation $\left(t_{C}=t_{K}\right)$, and late commutation $\left(t_{C}>t_{K}\right)$.

4.1. Thrust Drop under Premature Commutation. Because the thrust time curve is a periodic function, the average thrust can be calculated from half of a period. In this case, the thrust

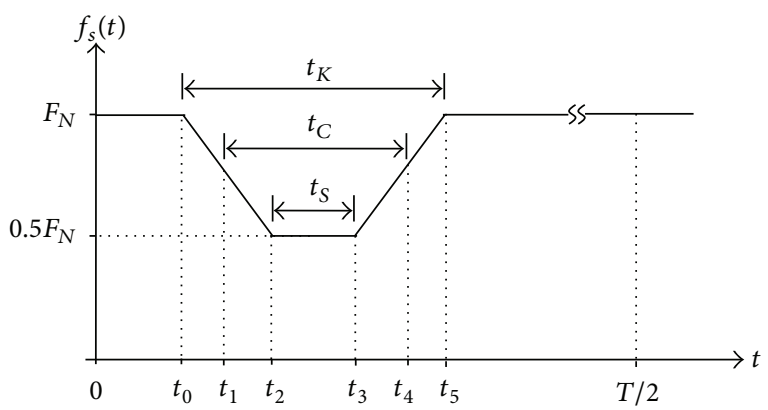

FIGURE 3: Thrust time curve at the premature commutation type $\left(t_{C}<t_{K}\right)$.

time curve is shown in Figure 3. The thrust time function can be represented by (10)

$$
f_{s}(t)= \begin{cases}\frac{F_{N},}{F_{N}}\left(1+\frac{t-t_{2}}{t_{0}-t_{2}}\right), & t_{0}<t \leq t_{2} \\ \frac{F_{N}}{2}, & t_{2}<t \leq t_{3} \\ \frac{F_{N}}{2}\left(1+\frac{t-t_{3}}{t_{5}-t_{3}}\right), & t_{3}<t \leq t_{5} \\ F_{N}, & t_{5}<t \leq \frac{T}{2},\end{cases}
$$

where $t_{0}$ is the time point for turning down of the stator current and $t_{1}$ is the beginning of stator section changing. The other parameters are defined in Section 3. During the stator section changing, the train thrust will be also changed and causes a jerk. The jerk $r(t)$ at premature commutation can be expressed in (11)

$$
r(t)= \begin{cases}0, & 0 \leq t \leq t_{0} \\ \frac{F_{N}}{2 m\left(t_{0}-t_{2}\right)}, & t_{0}<t \leq t_{2} \\ 0, & t_{2}<t \leq t_{3} \\ \frac{F_{N}}{2 m\left(t_{5}-t_{3}\right)}, & t_{3}<t \leq t_{5} \\ 0, & t_{5}<t \leq \frac{T}{2} .\end{cases}
$$




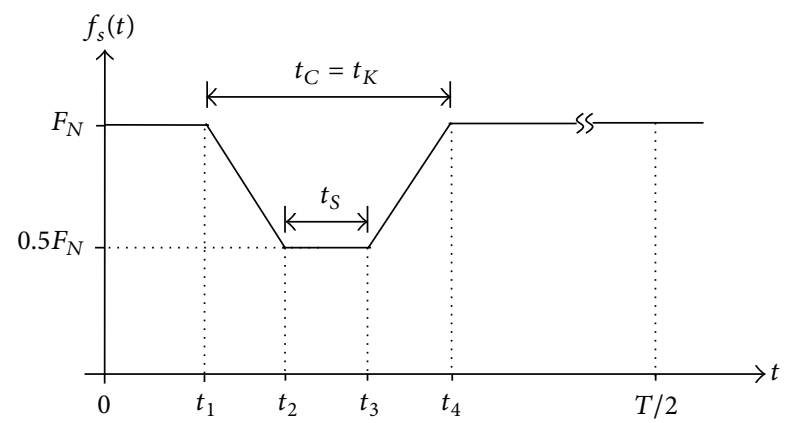

FIGURE 4: Thrust time curve at the simultaneous commutation type $\left(t_{C}=t_{K}\right)$.

The arithmetic thrust $F_{\mathrm{av}}$ can be calculated with reference to (9)-(11) and Figure 3 as (12)

$$
F_{\mathrm{av}}=F_{N}\left[\frac{v}{l_{M}}\left(\frac{l_{M}}{v}-t_{s}-\frac{F_{N}}{2 m r}\right)\right] .
$$

Obviously, the arithmetic thrust $F_{\mathrm{av}}$ depends on parameters jerk $r$, speed $v$, mass of vehicle $m$, and motor stator section length $l_{M}$.

4.2. Thrust Drop under Simultaneous Commutation. The calculation of the arithmetic value of the thrust in this case is the same as at premature commutation. Comparing Figures 3 and 4 , we can find that the thrust curves are almost identical. Only the change time and commutation time are different. From Figure 4, the time function of thrust $f_{s}(t)$ and jerk $r(t)$ are formulated in (13) and (14), respectively

$$
\begin{aligned}
& f_{s}(t)= \begin{cases}F_{N}, & 0 \leq t \leq t_{1} \\
\frac{F_{N}}{2}\left(1+\frac{t-t_{1}}{t_{1}-t_{2}}\right), & t_{1}<t \leq t_{2} \\
\frac{F_{N}}{2} & t_{2}<t \leq t_{3} \\
\frac{F_{N}}{2}\left(1+\frac{t-t_{3}}{t_{4}-t_{3}}\right), & t_{3}<t \leq t_{4} \\
F_{N}, & t_{4}<t \leq \frac{T}{2}\end{cases} \\
& r(t)= \begin{cases}0, & 0 \leq t \leq t_{1} \\
\frac{F_{N}}{2 m\left(t_{1}-t_{2}\right)}, & t_{1}<t \leq t_{2} \\
0, & t_{2}<t \leq t_{3} \\
\frac{F_{N}}{2 m\left(t_{4}-t_{3}\right)}, & t_{3}<t \leq t_{4} \\
0, & t_{4}<t \leq \frac{T}{2} .\end{cases}
\end{aligned}
$$

With reference to (9), (13), and (14), the arithmetic thrust $F_{\mathrm{av}}$ at premature commutation can also be calculated from (12)

4.3. Thrust Drop under Late Commutation. If the train travels slower than the reference speed $v_{S}$, the change-step mode

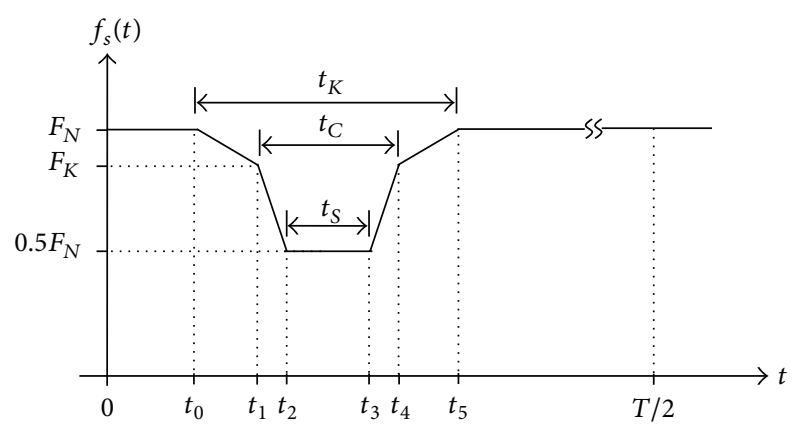

FIgURE 5: Thrust time curve at late commutation $\left(t_{C}>t_{K}\right)$.

is operated with late commutation. In this case, the thrust time curve for one time stator section changing is shown in Figure 5 and the time function is in (15)

$$
f_{s}(t)= \begin{cases}F_{N}, & 0 \leq t \leq t_{0} \\ F_{K}+\left(F_{N}-F_{K}\right)\left(\frac{t-t_{1}}{t_{0}-t_{1}}\right), & t_{0}<t \leq t_{1} \\ \frac{F_{N}}{2}+\left(F_{K}-\frac{F_{N}}{2}\right)\left(\frac{t-t_{2}}{t_{1}-t_{2}}\right), & t_{1}<t \leq t_{2} \\ \frac{F_{N}}{2}, & t_{2}<t \leq t_{3} \\ \frac{F_{N}}{2}+\left(F_{K}-\frac{F_{N}}{2}\right)\left(\frac{t-t_{3}}{t_{4}-t_{3}}\right), & t_{3}<t \leq t_{4} \\ F_{K}+\left(F_{N}-F_{K}\right)\left(\frac{t-t_{4}}{t_{5}-t_{4}}\right), & t_{4}<t \leq t_{5} \\ F_{N}, & t_{5}<t \leq \frac{T}{2} .\end{cases}
$$

In Figure 5, the force $F_{K}$ is the thrust at commutation beginning of the stator current. It can be determined by (16)

$$
F_{K}=\frac{F_{N}}{2}\left(2-\frac{t_{1}-t_{0}}{t_{C}}\right) .
$$

The jerk $r(t)$ at late commutation is expressed in (17)

$$
r(t)= \begin{cases}0, & 0 \leq t \leq t_{0} \\ \frac{F_{N}-F_{K}}{m}\left(\frac{1}{t_{0}-t_{1}}\right), & t_{0}<t \leq t_{1} \\ \frac{2 F_{K}-F_{N}}{2 m}\left(\frac{1}{t_{1}-t_{2}}\right), & t_{1}<t \leq t_{2} \\ 0, & t_{2}<t \leq t_{3} \\ \frac{2 F_{K}-F_{N}}{2 m}\left(\frac{1}{t_{4}-t_{3}}\right), & t_{3}<t \leq t_{4} \\ \frac{F_{N}-F_{K}}{m}\left(\frac{1}{t_{5}-t_{4}}\right), & t_{4}<t \leq t_{5} \\ 0, & t_{5}<t \leq \frac{T}{2} .\end{cases}
$$




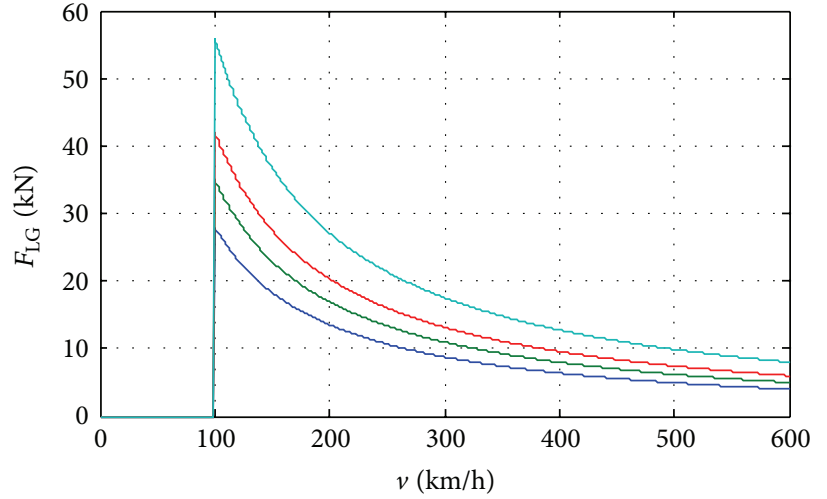

(a) The resistance from a linear generator

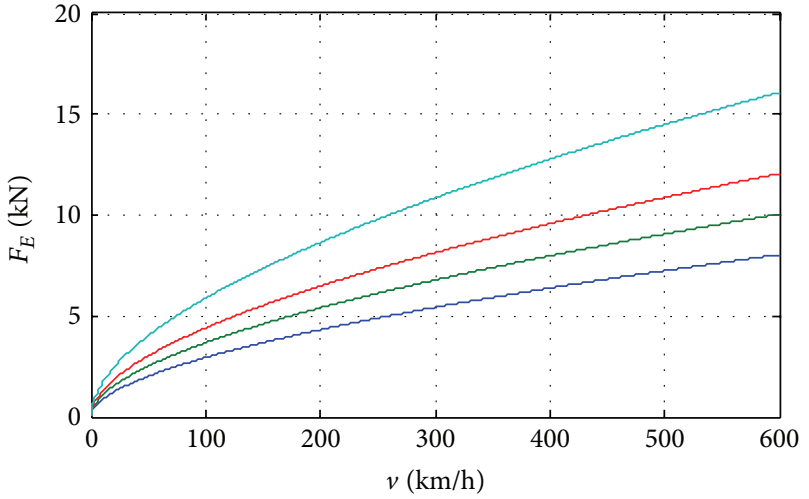

(b) The resistance of eddy current from guidance

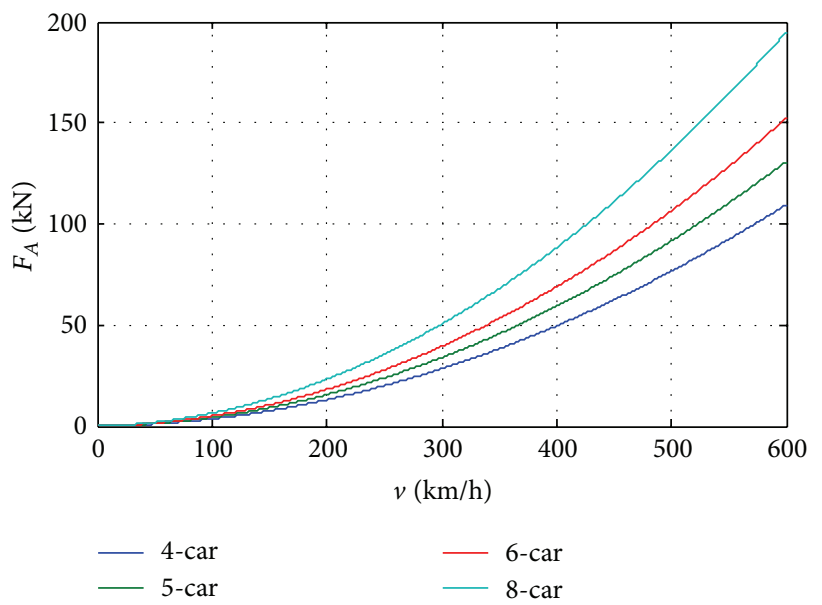

(c) Aerodynamic resistance

FIGURE 6: Three different running resistances of maglev trains.

Similarly, the arithmetic thrust can be calculated according to (9), (16), and (17) as (18)

$$
\begin{aligned}
F_{\mathrm{av}}= & F_{N} \cdot \frac{v}{l_{M}} \\
& \times\left\{\frac{v}{v F_{N}-2 m r l_{v}}\left(m r t_{s}-\frac{m r l_{v}}{v}+F_{N}\right)\right. \\
& \left.\cdot\left[\frac{F_{N}}{2 m r}-\frac{1}{2}\left(\frac{l_{v}}{v}-t_{s}\right)\right]+\frac{l_{M}}{v}-\frac{F_{N}}{2 m r}-t_{s}\right\} .
\end{aligned}
$$

It is obvious that (18) provides one more influential parameter (i.e., $l_{v}$ ) than (12) does. The reason for this result is the train has two different jerks during the stator section changing period. The first jerk takes place if the vehicle is leaving the present stator section without reducing or increasing the stator current. The second jerk occurs when the stator current is adjusted from full-load to zero or reversely. The duration of this jerk depends on the vehicle length.

\section{Results and Discussion}

In the following quantitative analyses, the influential parameters on thrust including train speed, jerk, and stator section length are selected as variables. In general, the train speed is set from 300 to $500 \mathrm{~km} / \mathrm{h}$ because a maglev vehicle travels more appropriately for a long distance commercial line under this speed limitation. The jerk can be reasonably chosen between 0.1 and $0.5 \mathrm{~m} / \mathrm{s}^{3}$. However, the decision of a proper jerk depends on driving comfort. And, the stator section length can be selected with reference to the test facility Emsland in Germany between 900 and $1350 \mathrm{~m}$ in changestep mode [13]. The train mass is represented by vehicle cars. For the long distance commercial line, a maglev train is favorably made by $4,5,6$, or 8 cars in accordance with the number of passengers. As the last parameter, switch time is set to $500 \mathrm{~ms}$ as mentioned in Section 3. In order to obtain the corresponding thrust $F_{N}$, the running resistance must be determined first.

5.1. Running Resistance. As in Section 3, the three parts of the running resistance of the maglev train can be calculated from (5)-(7). And, the results are shown in Figures 6(a)6(c). Figure 6(a) shows the running resistance from a linear 


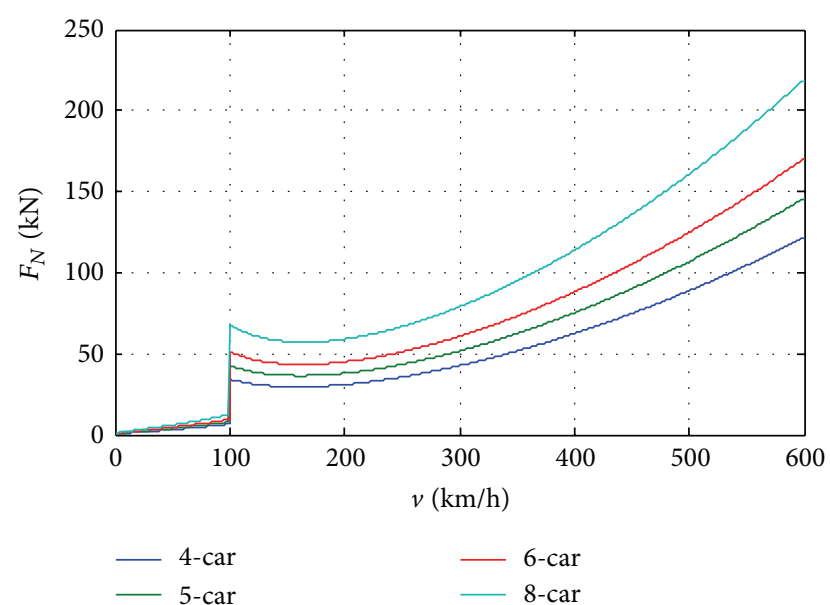

FIGURE 7: The total running resistance of maglev trains.

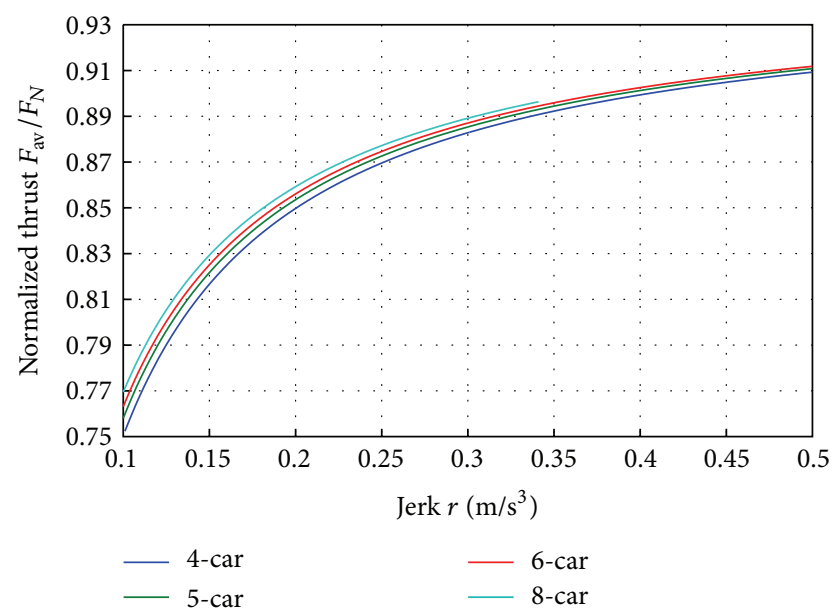

Figure 8: Arithmetic thrust as a function of jerk under $t_{C}<t_{K}(v=$ $470 \mathrm{~km} / \mathrm{h}, l_{M}=1280 \mathrm{~m}$ ).

generator. It appears when the train speed reaches $100 \mathrm{~km} / \mathrm{h}$. This means that the linear generator has come into service until the train speeds up to $100 \mathrm{~km} / \mathrm{h}$. The resistance of eddy current from guidance and the aerodynamic resistance are represented in Figures 6(b) and 6(c), respectively.

Comparing Figures 6(a)-6(c), it is good to know that the aerodynamic resistance is dominant when the train travels at a high speed $(>300 \mathrm{~km} / \mathrm{h})$. The total running resistance is shown in Figure 7 and indicates the required thrust to drive the maglev train.

5.2. Thrust Losses. Theoretical analysis of thrust during stator section changing was completed in Section 4. Because the jerk and the train speed are the most important influential parameters on thrust, the following analyses will be based on these two parameters. The calculation results at premature commutation are shown in Figures 8 and 9. For the ease of reading, the average thrust will be normalized with rated thrust. Figure 8 presents the influence of the jerk on the arithmetic thrust $F_{\mathrm{av}}$. Figure 9 shows the arithmetic thrust

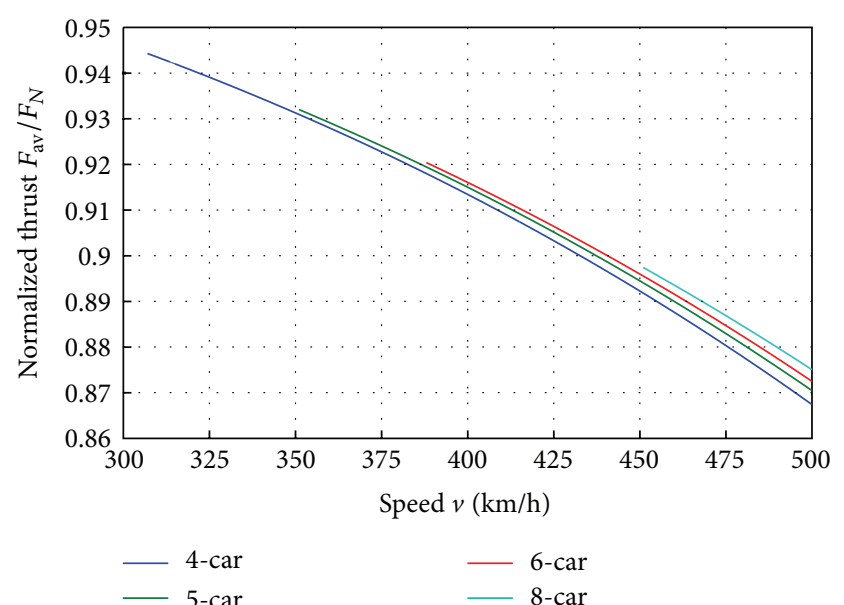

Figure 9: Arithmetic thrust as a function of speed under $t_{C}<$ $t_{K}\left(r=0.3 \mathrm{~m} / \mathrm{s}^{3}, l_{M}=1280 \mathrm{~m}\right)$.

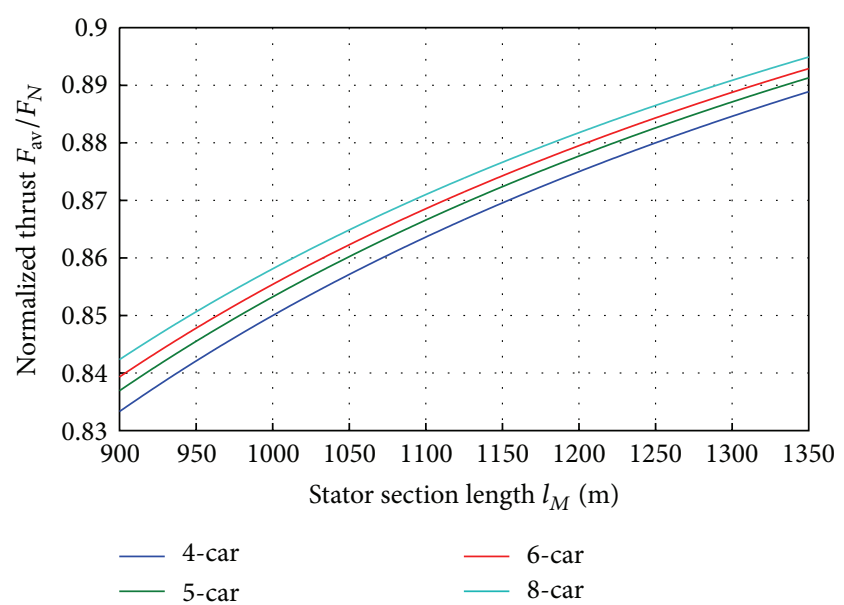

FIgURE 10: Arithmetic thrust as a function of stator section length under $t_{C}<t_{K}\left(r=0.3 \mathrm{~m} / \mathrm{s}^{3}, v=470 \mathrm{~km} / \mathrm{h}\right)$.

$F_{\text {av }}$ as a function of speed. From the calculation results, we know that the thrust drop becomes larger when the travel speed is higher. Among them, the parameter jerk $r$ is the most important factor because the thrust drop becomes larger with a smaller jerk under premature commutation. However, the thrust drop and jerk are in conflict with each other. One must find a compromise between them, especially at high speeds. In addition, the stator section length also affects thrust losses. The influence of stator section length on thrust is shown in Figure 10. The thrust losses become smaller, when the stator section length is longer. However, a longer stator section can lead to less efficiency of the linear synchronous motor. Therefore, a compromise between thrust and efficiency is required.

The calculation of thrust under simultaneous commutation type is the same as in premature commutation type. The variation of thrust in this case is similar to premature commutation. In fact, the simultaneous commutation type rarely occurs in actual operation because a maglev train 


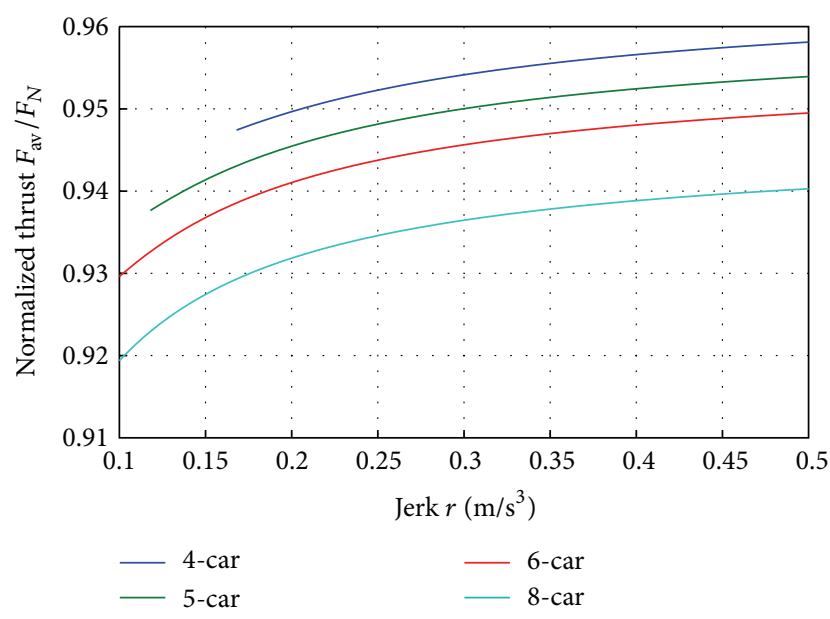

Figure 11: Arithmetic thrust as a function of jerk under $t_{C}>t_{K}(v=$ $280 \mathrm{~km} / \mathrm{h}, l_{M}=1280 \mathrm{~m}$ ).

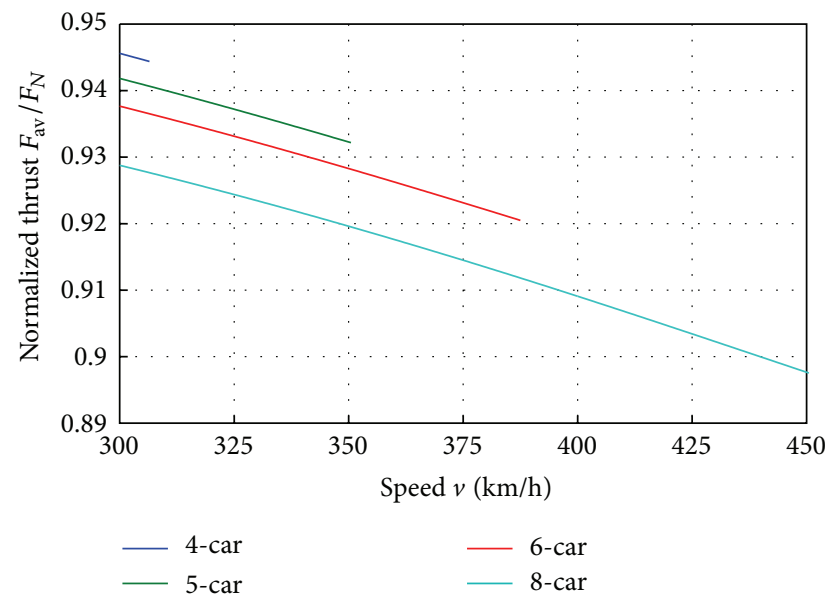

Figure 12: Arithmetic thrust as a function of speed under $t_{C}>$ $t_{K}\left(r=0.3 \mathrm{~m} / \mathrm{s}^{3}, l_{M}=1280 \mathrm{~m}\right)$.

with a selected jerk has only one speed for simultaneous commutation (see Table 1). In general, this speed is not equal to the operating speed.

From (18), the calculated results of the average thrust under late commutation are presented in Figures 11, 12, and 13 , suggesting a higher average thrust in comparison with premature commutation type. The reason for this phenomenon is that the late commutation is better applied to lower speed. In addition, the late commutation has lower thrust losses with fewer train cars under the same jerk and stator section length. In other words, the maglev train operated in late commutation type is suitable for fewer cars. Conversely, a longer maglev train is better for premature commutation type.

\section{Conclusions}

The propulsion technology of high-speed maglev systems using the change-step mode has been described in this paper.

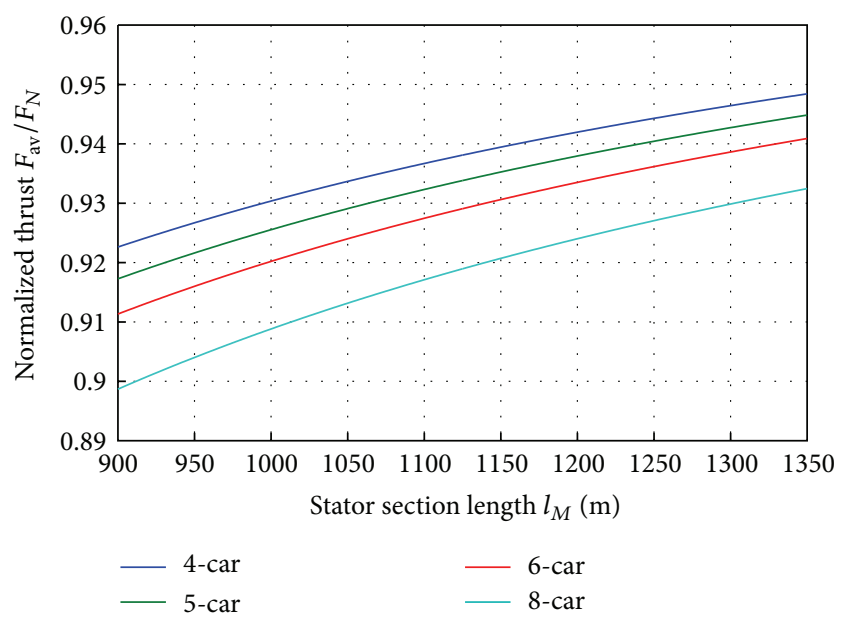

FIgURE 13: Arithmetic thrust as a function of stator section length under $t_{C}>t_{K}\left(r=0.3 \mathrm{~m} / \mathrm{s}^{3}, v=300 \mathrm{~km} / \mathrm{h}\right)$.

The thrust losses of the change-step mode for each commutation type are also calculated. The operational parameters have different potency on thrust. Among these parameters, the limited jerk and running speed affect the thrust evidently. For lower thrust losses, the maglev train should travel at high speed with more cars, conversely, at low speed for fewer cars. For example, if a maglev train travels with speed $470 \mathrm{~km} / \mathrm{h}$ and jerk $0.3 \mathrm{~m} / \mathrm{s}^{3}$ under premature commutation, the 8 -car combination has the lowest thrust losses. Similarly, the 4car combination obtains the lowest thrust losses when a train runs at a speed of $280 \mathrm{~km} / \mathrm{h}$ and jerk $0.3 \mathrm{~m} / \mathrm{s}^{3}$ under late commutation. These calculated results can provide a better solution for operating the high-speed maglev train. In addition, the thrust losses that were studied in this paper can lead to a speed drop of maglev trains. This is also a disadvantage by using the proposed change-step mode. Concerning how thrust losses affect the speed of maglev trains, it is the research issue in the future.

\section{Acknowledgments}

This work was supported by the National Yunlin University of Science and Technology and by the National Science Council of Taiwan under Grant NSC 100-2221-E-224-003. The author also wishes to express his appreciation to Ya-Tong Chang for drawing the diagrams.

\section{References}

[1] W. Leonhard, R. G. Rhodes, and J. H. Rakels, "Technical alternatives for a Maglev system," Electronics and Power, vol. 24, no. 4, pp. 293-296, 1978.

[2] H. Yaghoubi, “The most important Maglev applications," Journal of Engineering, vol. 2013, Article ID 537986, 19 pages, 2013.

[3] A. Cassat and M. Jufer, "MAGLEV projects technology aspects and choices," IEEE Transactions on Applied Superconductivity, vol. 12, no. 1, pp. 915-925, 2002. 
[4] W. W. Dickhart, "Status of transrapid Maglev," in Electro International, pp. 613-617, 1991.

[5] H.-W. Lee, K.-C. Kim, and J. Lee, "Review of Maglev train technologies," IEEE Transactions on Magnetics, vol. 42, no. 7, pp. 1917-1925, 2006.

[6] K. Davey, "Analysis of an electrodynamic Maglev system," IEEE Transactions on Magnetics, vol. 35, no. 5, pp. 4259-4267, 1999.

[7] M. Ono, S. Koga, and H. Ohtsuki, "Japan's superconducting Maglev train," IEEE Instrumentation and Measurement Magazine, vol. 5, no. 1, pp. 9-15, 2002.

[8] R. Hellinger and P. Mnich, "Linear motor-powered transportation: history, present status, and future outlook," Proceedings of the IEEE, vol. 97, no. 11, pp. 1892-1900, 2009.

[9] B. M. Perreault, "Optimizing operation of segmented stator linear synchronous motors," Proceedings of the IEEE, vol. 97, no. 11, pp. 1777-1785, 2009.

[10] H. Ikeda, S. Kaga, Y. Osada et al., "Development of power supply system for Yamanashi Maglev test line," in Proceedings of the Power Conversion Conference, vol. 1, pp. 37-41, Nagaoka Japan, August 1997.

[11] T. Sakamoto and T. Shiromizu, "Propulsion control of superconducting linear synchronous motor vehicle," IEEE Transactions on Magnetics, vol. 33, no. 5, pp. 3460-3462, 1997.

[12] R. Fischperer, Magnetschnellbahn für den schnellen Regionalverkehr Optimierung des Langstatorantriebs und der Energieversorgung [Ph.D. thesis], Technische Universität Berlin, Berlin, Germany, 2006.

[13] R. Fürst, Anwendungsnahe Dimensionierung und messtechnische überprüfung von Langstator-Linearmotoren für Magnetschnellbahnen [Ph.D. thesis], Technische Universität Berlin, Berlin, Germany, 1993.

[14] X. Wang, H. Liu, and S. Zhang, "High performance propulsion control of magnetic levitation vehicle long stator linear synchronous motor," in International Conference on Electrical Machines and Systems (ICEMS '11), pp. 20-23, August 2011.

[15] R. Schah, P. Jehle, and R. Naumann, Transrapid und Rad-Schienen-Hochgeschwindigkeitsbahn, Ein gesamtlicher Systemvergleich, Springer, Berlin, Germany, 2006.

[16] P. Mnich, "Die Bahnen und die Magnefahrtechnik in Japan und Deutschland," ETR_Eisenbahntechnische Rundschau, vol. 46, no. 12, pp. 816-824, 1997.

[17] R. D. Thornton, "Efficient and affordable Maglev opportunities in the united states," Proceedings of the IEEE, vol. 97, no. 11, pp. 1901-1921, 2009. 


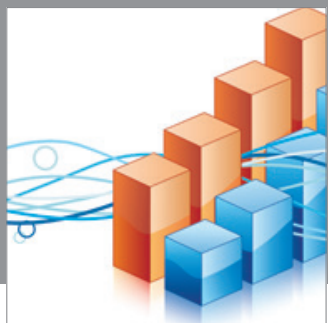

Advances in

Operations Research

mansans

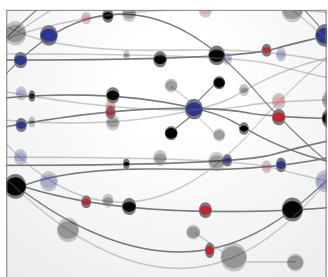

The Scientific World Journal
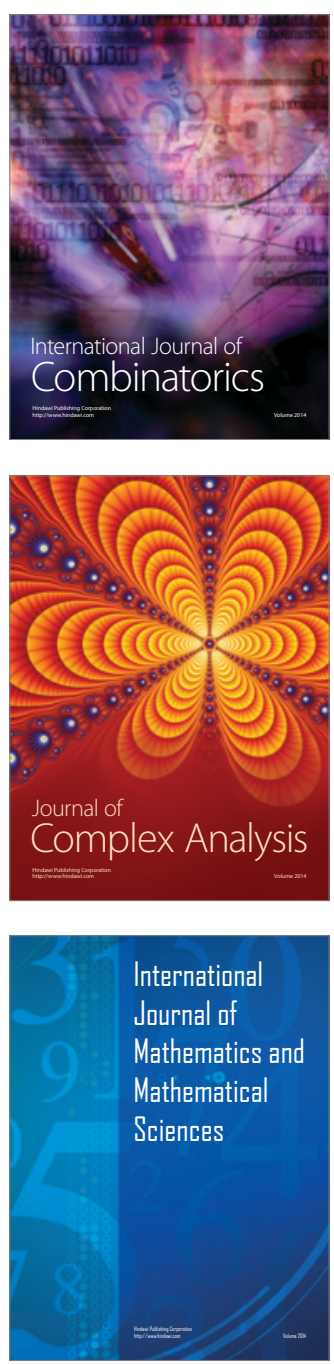
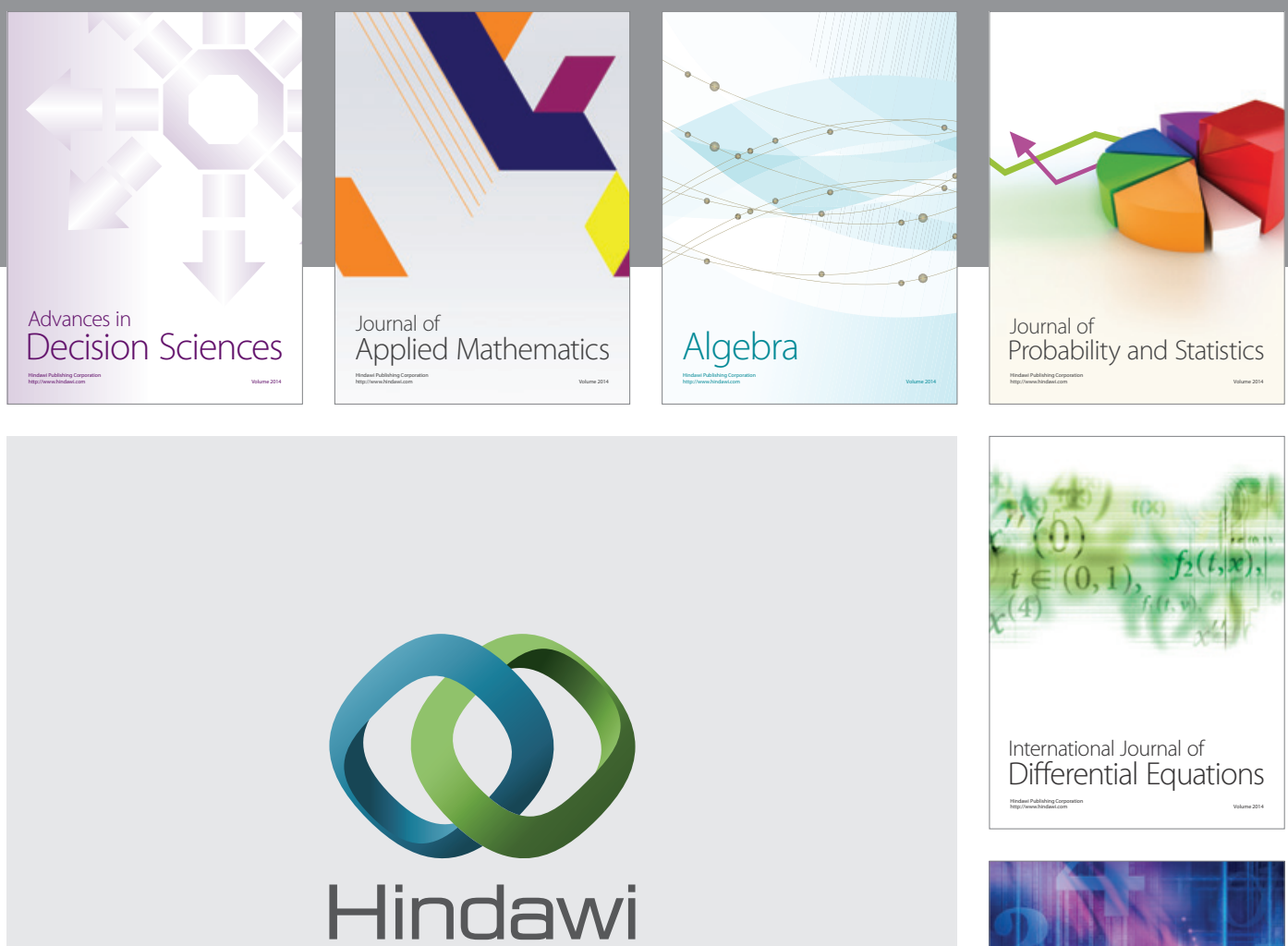

Submit your manuscripts at http://www.hindawi.com
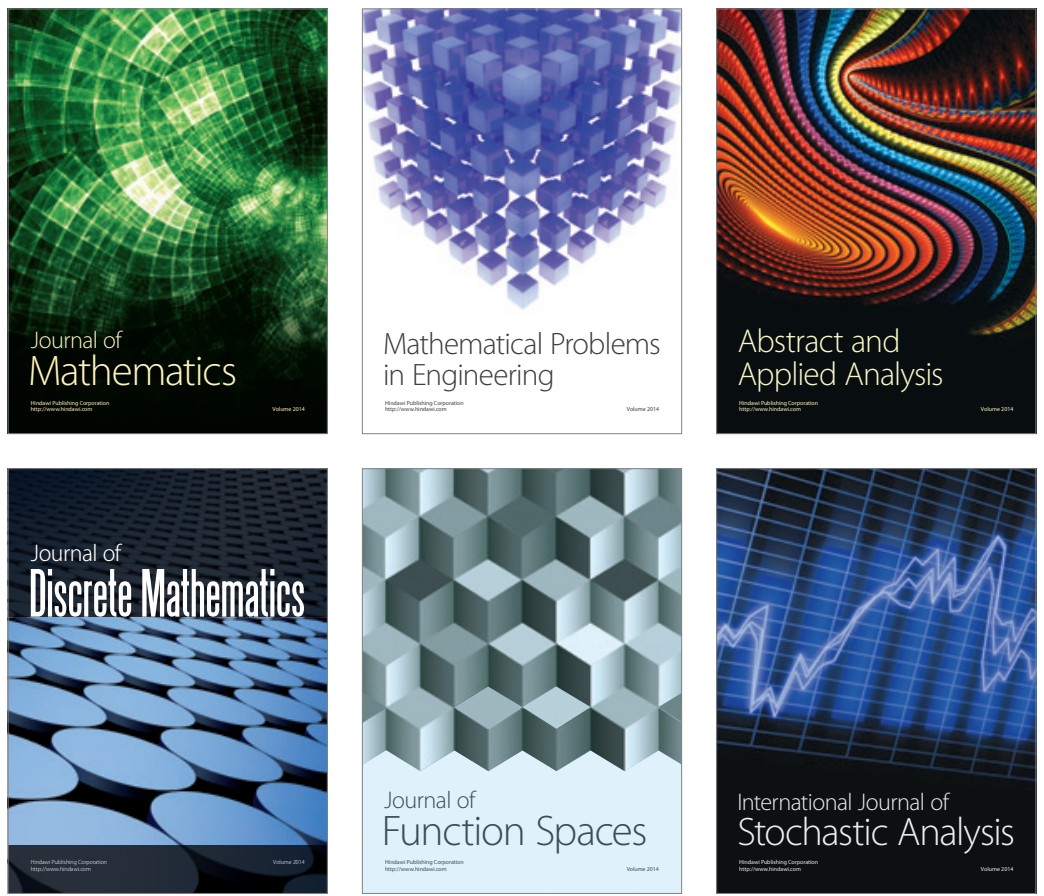

Journal of

Function Spaces

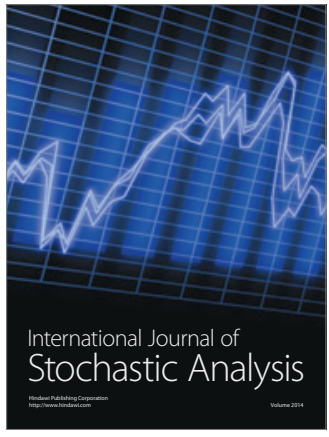

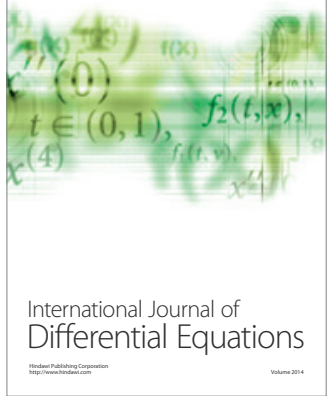
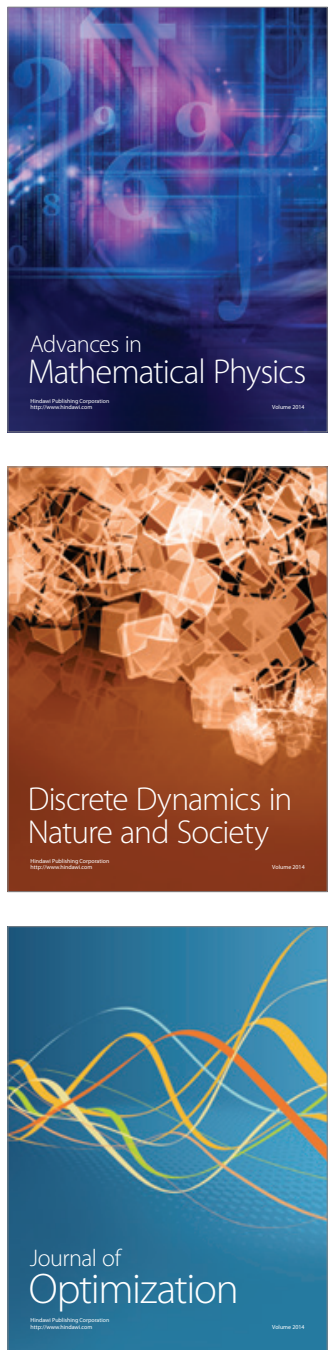